\title{
Ciência da Informação e o mundo neoliberal
}

\author{
Ciencia de la información y mundo neoliberal
}

Information Science and the neoliberal world

\begin{abstract}
BIANCA GonçALVES DE SOUZA
Programa de Pós Graduação em Ciência da Informação da Universidade Federal Fluminense. E-mail: biancagsouza@yahoo.com.br
\end{abstract}

\section{Resumen}

Este artículo culmina diez años de conversaciones entre Eduardo Murguía y la autora en torno a la relación entre el desarrollo de las ciencias de la información y el mundo neoliberal. La hipótesis subyacente es que la Ciencia de la Información es la ciencia neoliberal por excelencia. Para basar esta afirmación, se exploran los caminos transitados hasta el concepto contemporáneo de investigación científica, a través del neoliberalismo y la posmodernidad, con la ayuda de diferentes estudiosos de los campos de la Ciencia de la Información, la Sociología y la Antropología. Como conclusión, se ofrecen tres posibilidades para seguir pensando la hipótesis de la Murguía, la de que la Ciencia de la Información es la gran ciencia neoliberal.

Palabras clave: Modernidad. Posmodernidad. Neoliberalismo. Ciencia de la información. Murguía Marañón, Eduardo Ismael.

\section{Prólogo}

Trabalhei uma década com o professor Eduardo Ismael Murguia. Boa parte desse tempo discutindo o tema do documento, o qual não deixa de estar presente nesse artigo também, ainda que em entrelinhas e nas leituras de compreensão do seu corpo textual. Nos últimos anos (2014 e 2015), por conta do pós-doutorado que cumpro junto ao Programa de Pós-Graduação da Universidade Federal Fluminense (UFF) em Niterói/RJ/Brasil, a ênfase desse professor, então supervisor, era trabalhar o documento a partir de Paul Otlet (2007), relacionando seu trabalho com os chamados neodocumentalistas, até que entrássemos na atual discussão da teoria ator-rede, tão bem exemplificada nos trabalhos de Bruno Latour (2012).

No entanto, esse texto se tratava de uma encomenda do professor Murguia. Serviço que não era minha praxe e nem a dele. Não por encomenda; tudo que era escrito, especialmente as dissertações e teses de seus alunos eram fruto de um processo que ele chamava de imersão. Alguns dias, mais noites e madrugadas do que manhãs, discutindo, conversando, entre cafés e chás, escrita, algumas leituras. Assim ficávamos três, quatros dias, dos quais resultava ao menos

\begin{abstract}
This article culminates ten years of conversations between Eduardo Murguia and the author around the relation between the development of Information Science and the neoliberal world. The underlying hypothesis is that Information Science is the neoliberal science par excellence. To ground this claim, the ways towards the contemporary concept of scientific research, through neoliberalism and post-modernity, are explored, with the aid of different scholars from the fields of Information Science, Sociology and Anthropology. As a conclusion, three possibilities are offered to keep thinking about the Murguia's hypothesis, that of Information Science being the great neoliberal science.
\end{abstract}

Keywords: Modernity. Post-Modernity. Neoliberalism. Information Science. Murguía Marañón, Eduardo Ismael.

uma estrutura e dessa saíam os bons trabalhos que ele produziu e os outros tantos que fez com seus alunos. Ele havia me solicitado rapidamente, que o fizesse, sem imersão, pois não havia tempo nem disponibilidade. Pois bem, esse texto é fruto de uma imersão nos meus livros, no som do teclado do meu computador e nas ideias que imagino que ainda possa compartilhar com ele.

Eram divagações que voavam no seguinte sentido: após a $2^{\mathrm{a}}$ Guerra Mundial ( $\left.2^{\mathrm{a}} \mathrm{GM}\right)$, sabidamente, o mundo havia se transformado e como ele a ciência. Após esse processo de transformação, especialmente para o mundo ocidental, é que se consolidou a Ciência da Informação e Documentação, assim como lá naquele tempo Paul Otlet (2007) já pensava - ainda antes da citada guerra - em seus trabalhos inicialmente publicados na década de 1930.

O professor Eduardo sempre lembrava a participação do autor belga na criação do projeto que originou no pós-guerra a Organização das $\mathrm{Na}$ ções Unidas (ONU) e todas as entidades e políticas de atuação frente aos países-membro. Nesse ponto poder-se-ia destacar que meu interlocutor tratava de expectativas quanto ao mundo no período após 1945, da declaração do final da 
$2^{\mathrm{a}}$ Grande Guerra, do surgimento da ONU e da reorganização de uma parte do mundo destruída e devastada social, material e economicamente. Mas as conversas não pararam por aí. Até a última semana de maio de 2015 , a cabeça dele fervilhava em torno desse assunto, pedindo-me referências sobre autores neoliberalistas.

Certa vez, repentinamente, ele somou ao debate outra ideia: a de que no período pós-guerra, economicamente denominado como Neoliberalismo, com o fim do chamado Estado de bem-estar social e com a retomada dos princípios liberais relidos e trabalhados por autores como Friedrich von Hayek (1946), Ludwig von Mises (1977), Milton Friedman (1985), e outros, revelava-se uma economia mais flexível. E esse momento pediria uma ciência que fosse também compatível. E nesse ponto o mestre propôs uma hipótese: a de que a Ciência da Informação viria a ser a ciência por excelência da contemporaneidade, encarnaria as vestes de ciência neoliberal.

\section{Introdução}

Importante ressaltar que o período em foco é denominado por teóricos como modernidade, e essa tinha um projeto próprio (Harvey, 1998, p. 23):

O domínio científico da natureza prometia liberdade da escassez, da necessidade e da arbitrariedade das calamidades naturais. $O$ desenvolvimento de formas racionais de organização social e de modos racionais de pensamento prometia a libertação das irracionalidades do mito, da religião, da superstição, liberação do uso arbitrário do poder, bem como do lado sombrio da nossa própria natureza humana. Somente por meio de tal projeto poderiam as qualidades universitárias, eternas e imutáveis de toda a humanidade ser reveladas.

David Harvey (1998), ao longo do segundo capítulo de seu livro, desenvolve com maestria a análise da modernidade e do modernismo. Antes das duas guerras do início do século XX, o mundo ainda acreditava em um projeto mais iluminista quando ao ser humano, havia ainda uma proposta mais preocupada em lutar contra a exploração do homem pelo homem. Após a $1^{a}$ Guerra Mundial, o ideal iluminista caiu por terra, bem como a questão econômica passa a ser preocupante, com várias economias arruinadas.

Economicamente, o fordismo foi o modelo de produção próprio da modernidade, compreendendo o período que se inicia em 1914, com o aparecimento do Ford $\mathrm{T}$, até o início da década de 1970. Produção e consumo de massa, sistema de reprodução da força de trabalho, uma política de controle e de gerência dessa força de trabalho e, além disso, trazia uma nova proposta de sociedade e de psicologia, propunha uma sociedade democrática, racionalizada, modernista e populista. Outras características que merecem destaque são a centralização do capital presença de um corporativismo e de uma racionalidade burocrática.

Somava-se ao fordismo um Estado forte capaz de controlar ciclos econômicos, ou seja, promovendo um intervencionismo estatal em questões econômicas. Aqui se tinha a fórmula modelo fordista mais "administração econômica keynesiana mais controle de relações de salário" (Harvey, 1998 , p. 130). Porém, no período entre-guerras, houve resistência para a continuidade desse projeto e passou por modificações até chegar a um padrão de internacionalização, que foi o que o manteve firme até início da década de 1970 (Harvey, 1998). Vale apenas relembrar que já na década de 1960 também foi que percebeu um abalo no Estado de bem-estar social e no modelo keynesiano de Estado, crise que se encadeia econômica e culturalmente, com a modernidade.

A professora Maria Nélida González de Gómez, em um de seus artigos, ensina-nos com clareza o que foi o processo de diferenciação que se deu entre o período anterior à modernidade e com o advento dessa, no que dizer respeito ao fazer científico. Ela escreve (Gónzalez de Gómez, 2003, p. 2):

Movimento análogo daquele que separa o trabalho manual do trabalho intelectual, dissociava os saberes da vida privada (saber-viver, saber-falar, saberamar; saberes das mulheres, das crianças, dos anciãos) e dos saberes do fazer (como o saber prático dos artesãos) dos saberes institucionais, discursivos, transmissíveis, ensináveis e pelo tanto, codificados, potencialmente públicos, publicáveis e, finalmente, publicados.

Socializava-se assim o pesquisador no paradigma de uma especialidade ou disciplina, ao mesmo tempo em que se dissociavam entre si os novos coletivos de conhecedores: os físicos dos humanistas, os sociólogos dos matemáticos, os matemáticos dos engenheiros e, com muita ênfase, dissociavamse os cientistas, pesquisadores e especialistas, das pessoas comuns e os saberes habitualizados da vida cotidiana.

De fato, a objetivação e socialização intencional e sistemática dos conhecimentos tem sido um dos critérios para marcar a passagem das sociedades tradicionais e narrativas às modernas sociedades literárias, orientadas ao desenvolvimento científico e tecnológico.

Havendo uma modernidade, portanto, seguiu-se a ela uma pós-modernidade, ainda que não de uma maneira abrupta (Harvey, 1998, p. 53):

A maioria dos pensadores pós-modernos está fascinada pelas novas possibilidades da informação e 
da produção, análise e transferência do conhecimento.

É o tempo do fragmento, do volátil, de descontinuidades, da rejeição de metanarrativas; não havendo continuidade e preservação da memória, o historiador perde seu papel, entra em cena o arqueólogo do passado, que trabalhará com fragmentos apenas, pedaços aqui e ali espalhados para compreender a realidade tal como ela se coloca. Harvey (1998) cita o trabalho de Michel Foucault, Arqueologia do saber (2008, ed. or. 1969), do qual se desdobra o ofício do arqueólogo.

Já a pós-modernidade é mais recente e por hora, vale a pena menciona-la. No âmbito econômico o mundo abandona o modelo fordista e passa para uma acumulação flexível. Especialmente a partir de 1973, o modelo assume uma flexibilidade dos processos e dos mercados de trabalho, dos produtos e dos padrões de consumo, surgem novas maneiras de fornecimento de serviços financeiros, com ela surge um conceito importante chamado "compressão do espaço-tempo", no mundo capitalista os horizontes se estreitam, meios de comunicação, todavia ampliam possibilidades (Harvey, 1998, p. 151):

O próprio saber se torna uma mercadoria-chave, a ser adquirida e vendida a quem pagar mais, sob condições que são elas mesmas cada vez mais organizadas em bases competitivas.

As guerras mundiais que aconteceram na Europa que ocorreram nos interregnos de 1914-1918 e 1939-1945 se deram no ínterim do projeto moderno. O período que se seguiu ao final da $2^{a}$ Grande Guerra promoveu transformações relevantes em praticamente todo globo terrestre e, provavelmente, torne-se mais claro elucida-los agora após uma breve explicação de tais conceitos.

Exterminou-se a ameaça fascista na Europa, consolidando o grupo dos países aliados, foi dada a largada da chamada Guerra Fria e foi também, em 1945, que se fundou a Organização das Nações Unidas (ONU), uma organização que desejava fazer a manutenção da paz, principalmente, entre todas as nações. Paul Otlet (2007) e Henri de La Fontaine, antes mesmo da guerra, haviam pensado em alguma ideia que serviu de base para a formação dessa organização. E também no campo científico, Otlet já propunha a universalização do acesso à informação e à documentação, quando pensou na criação do Mundaneum, que se tratava de um centro científico, documental, educativo e social.

Também foi com o final da $2^{\mathrm{a}} \mathrm{GM}$ a transição para uma nova fase da economia, atendendo ao modelo fordista internacional, que ocorreu e especialmente em países ocidentais, o chamado Estado de bem-estar social. Tanto os Estados Unidos como países da Europa e América Latina se serviram de uma proposta de política de um estado paternalista, detentor das rédeas de quase todos os segmentos da vida social, inclusive no que dizia respeito à economia e à política. Entretanto, foi com as altas no valor do barril de petróleo de 1973 e 1975 que houve as primeiras rachaduras e crises nesse modelo estatal e governamental. Nesse período aparece outro modelo de economia baseado na acumulação flexível. Como ensinou Friedrich von Hayek (2011, p. 101), outro pensador liberal:

Probablemente la lección más significativa que se desprende de las vicisitudes políticas del siglo XX es la que nos muestra cómo el control de la parte material de la vida ha dado a los gobiernos —en los que hemos aprendido a llamar sistemas totalitarios - amplios poderes sobre la vida intelectual. Estamos en condiciones de perseguir nuestros propios fines sólo si una variada multiplicidad de fuentes pone a nuestra disposición los medios necesarios.

Milton Friedman (1985, p. 38) fez troça entre paternalistas e liberais, para explicar a diferença. "O paternalismo", na visão do autor, "é inevitável para aqueles que definimos como irresponsáveis". Diversamente da unidade operacional do modelo neoliberal que é o indivíduo, que faz suas escolhas e governa a si mesmo numa boa parcela de situações da vida cotidiana, o modelo paternalista tem por unidade a família. Friedman definiu o modelo paternalista como sendo mantenedor do controle econômico, político e social, em oposição ao liberal que promove competição, fornece estrutura monetária, evita intervenção estatal: "o liberal consistente não é um anarquista." (Friedman, 1985, p. 39). O Estado havia falhado na condução econômica de nações e, portanto, retornava ao mercado a competência para gerenciar dos mercados.

De maneira sucinta, o que se fez foi pincelar o cenário que será o ponto de partida desse artigo. É com o final da $2^{\mathrm{a}}$ Grande Guerra que haverá condições para se refletir: sobre a ciência e como esse se reorganizou no pós-guerra; e para pensar, no neoliberalismo, verificar quão relevante $e$ quão inserida está a Ciência da Informação e se ela tem por excelência a vocação de ser chamada por a ciência neoliberal.

Para realizar esse feito, o artigo será dividido em duas partes. Primeiramente, será feita a reflexão acerca da ciência no pós-guerra e para isso os trabalhos de Vannevar Bush, textos da Unesco, dentre outros serão fundamentais norteadores para compreender como a ciência conquistou 
seus espaços de atuação. Em segundo lugar, seguir-se-á uma reflexão sobre a hipótese acerca da ciência do documento e da informação e sua imprescindibilidade no mundo neoliberal.

A hipótese que o professor suscitou, portanto, foi a de que a Ciência da Informação seria, por excelência, a ciência claramente afeiçoada ao período conhecido como neoliberal. Ele conseguiu, de alguma maneira, reconhecer nela características que o fizeram pensar que a Ciência da Informação deveria ser coroada como uma ciência neoliberal. No entanto, esse enredo parece pedir uma resposta. Para encerrar o texto, uma terceira parte trará a reflexão de ideias do professor Eduardo Murguia sobre informação e ciência, para que se alinhavar, juntamente com as ideias do provocador desse artigo, a correlação entre informação, ciência e sociedade.

\section{Ciência: sua legitimação e validação no mundo moderno}

Pode se dizer que um divisor de águas para a ciência foi a $2^{a}$ Grande Guerra e, com o final dessa e com o surgimento da Unesco (Organização das Nações Unidas para Educação, Ciência e Cultura), especialmente a partir de 1945. O futuro da ciência, portanto, passa a interessar às nações desenvolvidas, bem como o seu controle (Unesco, 2006). Tanto os avanços conseguidos durante a guerra, como também os desastres, interessavam às nações no pós-guerra, ou porque não se desejava que acontecessem novamente (no caso de desastres), ou porque havia interesses econômicos voltados para os avanços tecnológicos alcançados durante o período belicoso.

Mas a questão que se pode incitar é a seguinte: por que a preocupação com o fazer científico especificamente? Porque havia uma preocupação com relação aos métodos utilizados para fazer a ciência, isto é, havia dúvida, havia incerteza quanto ao processo de legitimação da ciência em situações particularmente mencionadas durante a $2^{a} \mathrm{GM}$, como a ciência neofacista criticada pelos países aliados aos Estados Unidos. Como nos ensina Maria Nélida Gómez (2015, p. 343):

Reconhecida nos estudos da filosofia da ciência como a teoria dos três contextos, nessa concepção se afirma a relativa independência de três instâncias que intervêm na constituição dos conhecimentos científicos: o contexto de descoberta, sujeito a fatores psicológicos e subjetivos, à motivação e à imaginação, e se constitui ex ante do conhecimento dito propriamente científico; o contexto de demonstração, no qual fica constituída a cientificidade do científico, já que é o contexto da experimentação controlada, codificada e plausível de formalização probatória; e o contexto da aplicação, que é o mais sujeito aos interesses econômicos e políticos, mas que se constitui ex post a emergência do conhecimento científico.

Até a segunda metade do século $X X$, a tendência de preservar uma esfera autônoma de validade científica, reforçada pelo prestígio das formulações neopositivistas do contexto de justificação, sobretudo nas ciências físico-matemáticas, garantiam o predomínio dessa leitura epistemológica, e sua correspondência formal com os marcos normativos institucionais.

Os dois últimos contextos, de demonstração e de aplicação, eram os que mais preocupavam; o primeiro, pela necessidade que se julgou de haver um controle dos métodos científicos para que horrores como o de Hiroshima e Nagazaki novamente não acontecessem, bem como as tragédias ocorridas em campos de concentração com os chamados estudos feitos pelos cientistas nazistas. Mas por outro lado, e não menos importante, o contexto de aplicação revela os ganhos econômicos e o cenário político que estão amalgamados ao fazer científico. Nesse sentido, por exemplo, há que se lembrar, como o próprio livro da Unesco menciona, como o fim do colonialismo foi benéfico para o avanço das ciências, "foi o maior ponto de convergência para o estabelecimento das ciências dentro da Unesco", tanto para implementação de projetos, como para o avanço de mercados (Unesco, 2006, p. 33).

Juntamente com o fim da guerra na Europa, com o avanço do capitalismo, nos países que permaneceram aliados aos Estados Unidos, puderam esses promover em suas economias o avanço da industrialização. Conforme o desenvolvimento das indústrias acontecia, mesmo em países tidos como periféricos, subentendia-se que haveria um consequente avanço da ciência; a introdução da industrialização promoveria a chegada de novas tecnologias e subsequente desenvolvimento científico (Unesco, 2006).

Um exemplo elucidativo da visão da Unesco entre o que seria a ciência dita moderna realizada em países industrializados e países em desenvolvimento torna-se claro quando vislumbramos o Sistema de Informação para Ciência e Tecnologia das Nações Unidas (UNISIST). Somente a Unesco, dentre os organismos da ONU, gozava de um sistema de tratamento e organização da informação (Unesco, 2006).

Houve um momento alguns críticos de países em desenvolvimento criticaram esses modelos do UNISIST, dizendo que quem precisaria de ciência pura eram os países desenvolvidos, enquanto que aos países em desenvolvimento resta um grande interesse pelas ciências aplicadas, tecnológicas, que tragam soluções para o social e para problemas econômicos, longe de sistemas organizacionais e de ordenação do conhecimento. $O$ 
usuário da informação foi pensado como alguém semelhante ao indivíduo trabalhador de bases comunitárias, ou seja, alguém sem preparo algum para lidar com a informação, ou mesmo pensado como alguém completamente incapaz de conhecer e de se relacionar com a informação organizada (Unesco, 2006, p. 130).

Mas voltemos à discussão da validação e da autonomia da ciência. Como dito, até a Segunda Guerra Mundial a visão de ciência era pautada pelo escudo da modernidade, que discernia claramente o fazer científico de outros fazeres. $O$ fazer da ciência tinha um lócus próprio e gerava espaços institucionais próprios de saber e de produção do conhecimento. Para diferenciar esse período do seguinte, após da $2^{\mathrm{a}}$ Grande Guerra, chamemos esse período de o período de Ciência dos Anos de Ouro (CAO) (Oliveira, 2011), e associemos essa autonomia da ciência à teoria de Vannevar Bush (2008), denominando, portanto, de autonomia vannevariana.

Esse período que o autor Marcos Barbosa de Oliveira (2011, p. 531) denomina como o tempo da Ciência dos Anos de Ouro nada mais é que o interregno no qual o Estado assumiria a "função de principal financiador da pesquisa, sendo essa alocação de recursos públicos legitimada pelos benefícios para toda a sociedade decorrentes das aplicações do conhecimento científico gerado". Anteriormente já havia sido mencionado com relação à Unesco a preocupação dos países em controlar a produção da ciência e, nesse sentido, obviamente o controle estatal torna-se fundamental, fazendo dele o principal financiador.

A proposta de Vannevar Bush era a de que, "o Estado deve limitar-se a prover um volume global de recursos para a pesquisa, ficando sua distribuição a cargo da própria comunidade científica, em função do interesse intelectual e da pura curiosidade de seus membros" (Oliveira, 2011, p. 533). Esse modelo, por fim, combina perfeitamente com o que foi dito no início desse texto acerca da modernidade e seu projeto social, especialmente quando pensamos no projeto do Estado de bem-estar social do início do século $X X$. A proposta era de um controle, apesar de não o ser assim tão declarado, mas preocupado com os avanços que a ciência traria para a humanidade. Controle esse que ficava a cabo dos Estados, sem o risco de que grupos ou países - que não os capitalistas, especialmente - controlassem a grande produção científica mundial.

\section{A Ciência da Informação e do Documento e o contexto neoliberal}

A acima mencionada Ciência dos Anos de Ouro (CAO), que se restringiu particularmente, podemos dizer, até o final da década de 1960, com o fim dessa autonomia vannevariana transformouse consideravelmente. Teve-se a chamada crise do modelo de Estado de bem estar-social, bem como das propostas do pensamento keynesiano, seguida da crescente ascensão do pensamento neoliberalista, representada por vários autores, alguns já mencionados nesse artigo. Marcos Oliveira (2011, p. 534), compreende que:

O neoliberalismo pode ser caracterizado, no que tem de mais essencial, como a fase do capitalismo em que se exacerba a propensão do sistema a transformar todas as categorias de bens em mercadorias (...). A maior parte das políticas neoliberais incluindo a do Estado mínimo, com todas as suas implicações - são decorrência direta do objetivo de promover a mercantilização universal, e isso vale também para as políticas científicas e tecnológicas (PCT). Tais políticas, associadas à difusão do ideário neoliberal na comunidade científica, e a outros fatores da conjuntura econômica, tiveram um impacto profundo nas práticas científicas, resultando no que vamos denominar ciência neoliberal.

Em outras palavras, ciência torna-se item de mercado, mercantilizável. Além disso, é nesse período que começa haver o questionamento acerca da autonomia e da isenção da ciência e, especialmente após eventos vistos ao longo da guerra, tornava-se impossível ignorar evidências de critérios de validade e objetividade, juntamente com critérios de valor a serem questionados (Gónzalez De Gómez, 2015).

Como anteriormente exposto, no trabalho de Vannevar Bush (2008) é possível perceber uma autonomia própria da chamada Ciência dos Anos de Ouro, basicamente atrelada a uma política de Estado que a financia e dá coordenadas a respeito do assunto, o que se torna também evidente em algumas diretrizes observadas em políticas propostas pela Unesco (2006). Todavia, o neoliberalismo pede uma autonomia própria também, e essa consiste "na liberdade de cada cientista procurar financiamento para as pesquisas que deseja realizar em qualquer fonte, pública ou privada, tendo em vista apenas seu auto-interesse" (Oliveira, 2011, p. 535-536). Autonomização com relação à fonte financiadora, o pesquisador pode prescindir do Estado como fonte de financiamento, podendo buscar recursos na esfera privada.

Neoliberalismo e mercantilização são sinônimos nesse contexto. Em busca desses assuntos em artigos que reflitam sobre o tema, as ciências que 
aparecem - como sendo ciência de cunho neoliberal - são justamente as disciplinas associadas à biotecnologia e à biomedicina, pelo forte apelo mercadológico que possuem (1). Mas, de fato, como ocorreu esse processo de transformação tão radical dentro da ciência que afetou sua autonomia e sua validação?

Voltemos novamente o olhar para a Unesco e é possível perceber que nos anos de 1960 começaram a aparecer as primeiras políticas voltadas para a ciência; já era o período conhecido com Guerra Fria, no entanto os olhares da Unesco estavam voltados para os processos de crise dos países colonialistas especialmente na África. Mais do que isso, alguns pesquisadores europeus do pós-guerra perceberam que havia um hiato muito grande entre pesquisadores das áreas de ciências naturais e ciências exatas, assim como com ciências humanas. E naquele tempo, havia um grande contingente de cientistas chegando para se somar a esses, que eram os "sem status", por serem originários de países recémproclamados independentes (Unesco, 2006). Onde se encaixariam? Iniciava-se um regime de cientometria, ou seja, de medir a distribuição de cientistas em torno do planeta, bem como o nível e os recursos.

O neoliberalismo, portanto, além de ter intrínseco a si o caráter de mercantilização, também mensura dados e fatos a sua volta. A ciência tornouse também quantificável e mais um índice para medir a diferença entre nações tidas como desenvolvidas e não-desenvolvidas. Inegavelmente, no período que identificamos como neoliberalismo, a ciência assume um caráter de marcador de diferenças. Traz consigo uma proposta muitas vezes imbuída de um ideal nobre de diminuir diferenças e desigualdades, quando verdadeiramente, ainda que não intencionalmente, se presta a servir de marcador de desigualdades: quando mais científico mais desenvolvido, quando menos ciência houver, menos desenvolvimento tecnológico, econômico e humano há.

Ainda na década de 1990, o antropólogo Pierre Bourdieu (1998), no jornal Le Monde Diplomatique expressava sucintamente sua ideia acerca do neoliberalismo e acerca da capacidade de pensar-se a si próprio como uma descrição científica da realidade:

Cette théorie tutélaire est une purê fiction mathématique, fondée, des l'origine, sur une formidable abstration : celle qui, au nome d'une conception aussi etróite que stricte de la rationalité identifiée à la rationalité individuelle, consiste à mettre entre parenthèses les conditions économiques e sociales des dispositions rationnelles e des structures économiques qui sont la condition de leur exercise.
II suffit de penser, pour donner la mesure de l'omission, au seul système d'enseignement, que n'est jamais pris en compte en tant que tel en un temps où il joue un rôle déterminant dans la production des biens et des services, comme dans la production des producteurs. De cette sorte de faute originelle, inscrite dans le mythe walrasien de la «théorie pure», découlent tous le manques et tous le manquements de la discipline économique, et l'obstination fatale laquelle le s'accroche à l'opposition arbitraire qu'elle fait exister, par sa seule existence, entre la logique proprement économique, fondée sur la concurrence et porteuse d'efficacité, et la logique sociale, soumise à la règle de équité.

Para Bourdieu, então, o neoliberalismo, além do apelo econômico que ele não deixa de mencionar, pende para o lado de uma racionalidade individual e afasta-se da lógica social, favorecendo condições econômicas e disposições racionais que favorecem a estrutura econômica e, por conseguinte de mercado.

\section{Respostas à hipótese murguiana}

Tendo desenvolvido os tópicos de análise relacionados à hipótese levantada, cabe agora tentar apresentar algumas respostas. Respostas essas de minha inteira responsabilidade e que são, por assim dizer, o encerramento de um diálogo que durou uma década, fruto aí de reflexões minhas apenas, algumas conjuntas, mas que assinalam vieses pensados juntos para possíveis caminhos a serem traçados.

Uma primeira ideia pode tratar da ciência moderna, que se alicerçou no século XVIII quando se iniciou o disciplinamento de saberes, separando saberes científicos de saberes outros que não levavam essa denominação (Foucault, 2005, p. 217):

O século XVIII foi o século do disciplinamento dos saberes, ou seja, da organização interna de cada saber como disciplina tendo, em seu campo próprio, a um só tempo critérios de seleção que permitem descartar o falso saber, o não-saber, formas de normalização e de homogeneização dos conteúdos, formas de hierarquização e, enfim, uma organização interna de centralização desses saberes em torno de um tipo de axiomatização de fato.

Nesse período desaparece a figura do "cientistaamador", como Michel Foucault (2015, p. 219) mencionou, para o advento de uma espécie de "comunidade científica", com estatuto reconhecido, organizada em torno de um consenso, centralizado, direta ou indiretamente, pela aparelhagem estatal. Esse poder disciplinador que está atrelado à ciência dita moderna foi tão representativo que o autor exemplifica com a criação do Ministério da História na França, no final do sé- 
culo XVIII, no sentido de demonstrar quão centralizador o Estado foi do saber-poder científico, detendo seu fazer, a elaboração de seu discurso, a criação de acervos e arquivos (Foucault, 2005).

O antropólogo Claude Lévi-Strauss (1997), em seu clássico artigo $A$ ciência do concreto, formulou a diferença entre aquilo que ele entendia ser o pensamento selvagem e o pensamento civilizado, ou o que viemos até então chamando de ciência moderna. A ciência moderna, assim como a conhecemos, é classificatória, e não se mantém sem essa premissa. Tudo classifica e ordena, e essa realidade sempre supera o caos de uma realidade pré-existente, ou seja, pré-científica.

O que Lévi-Strauss (1997, p. 31) denominou como sendo a ciência do concreto divergia da ciência que atendiam aos moldes modernos; era uma obra embasada em mitos e ritos que preservava

modos de observação e de reflexão que foram adaptados a descobertas de tipo determinado: as que a natureza autorizava, a partir da organização e da explicação especulativa do mundo sensível em termos de sensível.

O autor produziu um exemplo que se tornou uma grande referência para estudos da Antropologia, quando se pensa na compreensão acerca do pensamento selvagem, do outro e da relação de alteridade. O pensamento mítico selvagem funciona como a bricolagem, uma espécie de bricolagem intelectual, heteróclita, tem projeto e repertório limitados, e esse último pode ser rearranjado conforme for necessário. Surge a figura do bricoleur, que se define pela sua instrumentalidade basicamente, "um dia, isso pode servir para alguma coisa", diria esse indivíduo.

Já a ciência se espelha no personagem de um engenheiro: tem plano de trabalho e etapas para cumprir. Para ele também há projeto. Mas o bricoleur sempre tem um pouco de si naquilo que reorganiza ou, sempre tem algo de residual nos fatos que reorganizou, enquanto que o engenheiro cria resultados em cima de estruturas que produz continuamente, suas hipóteses e teorias (Lévi-Strauss, 1997).

A ciência moderna, depois de vista sob essas perspectivas de análise, claramente é a ciência do mundo logo após o final da $2^{\mathrm{a}}$ Guerra Mundial, especialmente aquele regido pelo estar de bemestar social e que gozou da atuação de um Estado intervencionista com políticas de atuação na área da ciência e tecnologia, como os Estados Unidos, que ficam bem elucidados no exemplo da obra de Vannevar Bush (2008). É a ciência de uma autonomia limitada aos ditames do Estado, com liberdade restrita ás vontades de um poder maior que o dos pesquisadores e centros de pesquisa. Também é a ciência que organiza e classifica exaustivamente o mundo a sua volta, de forma a gerar todos os padrões possíveis de categorização.

Mas apropriando-se da figura sugerida por LéviStrauss, o bricoleur, esse trabalha com restos, pedaços, fragmentos, o que muito o faz se assemelhar ao sujeito pós-moderno, ou melhor dizendo, ao período que se inicia especialmente na década de 1970 e que ficou conhecido como pósmodernidade. $O$ pós-moderno ainda classifica e organiza o mundo e não o deixará de faze-lo, mas todas a teorias e garantias do mundo moderno entraram em crise, a validação da ciência pela chancela do Estado sucumbe - em parte pela ausência de recursos e pela crise econômica - e a autonomia da ciência, especialmente como vislumbrada pelo autor Vannevar Bush, que a via bastante atrelada à vontades de políticas de Estado, agora vive uma autonomia neoliberal, cujo parâmetro não é mais o Estado financiador, e sim o pesquisador e todas as possibilidades públicas e as incontáveis privadas que ele pode recorrer para gerar fundos para suas pesquisas.

O bricoleur, do pensamento selvagem lévistraussiano tinha alguma coisa de pós-moderno, ainda que idilicamente, pela capacidade de lidar com fragmentos, que é muito próprio do neoliberalismo. "A autonomia neoliberal tem como premissa maior o princípio central do neoliberalismo, isto é, a tese da excelência do mercado enquanto sistema regulador da vida econômica" (Oliveira, 2011, p. 536).

Uma segunda ideia que favorece a reflexão acerca da hipótese murguiana leva a refletir e diz respeito ao trabalho de Vannevar Bush, As we may think, publicado em 1945. Esse famoso artigo ficou conhecido porque nele o autor trata da figura do MEMEX, aquele que dentre muitos estudiosos é reconhecido como sendo o precursor dos computadores modernos. No entanto, Bush foi além dessa reflexão e há quem reconheça em seu trabalho uma vocação primordial que conduziu inicialmente a Ciência da Informação, balizando seu início, "esse artigo foi tomado simbolicamente como marco por muitos pesquisadores, por representar o momento do pós-guerra em que se abriu um campo de investigação aos cientistas" (Rabello, 2009, p. 193).

$\mathrm{E}$ o que isso possa ter representado para a Ciência da Informação $(\mathrm{Cl})$, para fazer dela uma ciência neoliberal? $\mathrm{O}$ autor supracitado dá uma pista que reforça como esse artigo de Bush corroborou para fazer da $\mathrm{Cl}$ uma ciência relevante em base 
do mundo científico no pós-guerra (RABELLO, 2009, p. 194):

Dessa forma, esse ensaio (As we may think) marcou os primórdios de uma orientação teórica da $\mathrm{Cl}$ calcada na solução de problemas por meio da tecnologia. O documento, na lógica do Memex, seria uma "unidade de memória" que poderia ser acionada de acordo com a necessidade do pesquisador no desenvolvimento de sua "pesquisa aplicada" para a produção do conhecimento tecnológico ou técnico-científico. Portanto, poderíamos dizer que a importância de Vannevar Bush para a $\mathrm{Cl}$ se situa em sua "antevisão" da pertinência instrumental da tecnologia para a resolução de problemas informacionais, particularmente em RI (recuperação da informação).

Essa possiblidade não seria propriamente uma resposta, e sim um caminho aberto pela Cl e para ela mesma, e não necessariamente condição que a faria uma ciência neoliberal, apesar da questão tecnológica que está em foco. No entanto, é mister destacar que no contexto mundial após a $2^{\text {a }}$ Guerra Mundial não haverá ciência que não lance mão cada vez mais de avanços tecnológicos em favor e em prol de resultados de suas pesquisas. Laboratórios e cientistas disputam entre si, tal qual acontece no mercado financeiro e econômico: se fábricas produzem seus artefatos, "os artigos, longe de serem os relatórios do que foi produzido na fábrica, são considerados pelos membros da equipe como os produtos de sua usina singular" (Latour e Woolgar,1997, p. 39).

Uma terceira resposta possível que ocorre ligase à questão levantada na citação acima de Bruno Latour, qual seja, a atualidade da produção científica. Cientistas produzem documentos, e à ciência cabe um fazer, uma inscrição literária contínua. "A visão que o observador tem do laboratório privilegia os documentos escritos e os dispositivos de inscrição" (Latour e Woolgar, 1997, p. 59). E ele prossegue dizendo que, quando temos em mãos essa inscrição, então esquecemos todas as etapas que precisamos percorrer para te-la, para produzi-la. E propondo uma etnografia do trabalho do cientista que ele mesmo fez, ele reconheceu que a função final da ciência é produzir artigos e mais artigos, uma "cadeia de operações de escrita", que vão desde os primeiros rabiscos até o artigo pronto e acabado publicado em uma revista de renome internacional. (Latour e Woolgar, 1997, p. 70).

E essa escrita é uma luta que o observador "pôde descrever a atividade do laboratório como uma luta constante para criar e fazer aceitar certos tipos particulares de enunciados" (Latour e Woolgar. 1997, p. 83).
Enunciados esses que estão em artigos, os quais se configuram como documentos. O documento é o suporte de excelência a ser observado, analisado e estudado pela Ciência da Informação, seja em que dimensões se queira pensa-lo, em que formatos ou tipologias possíveis. Passando pelo livro, ao objeto tridimensional e aos arquivos digitais, o documento está presente em qualquer ciência, pois todas elas escrevem, produzem artigos, precisam de enunciados para poderem demonstrar a verdade daquilo que estão falando ou dizendo. E essa, a verdade, não deixa de ser uma das funções (obsessão e sua razão de ser) do documento, isto é, função do documento como prova (Murguia, 2010, p. 126):

Desde essa perspectiva, o documento é verdadeiro porque ele prova, e prova demonstrando. O agenciamento da prova aparece com o pensamento grego, substituindo assim a autoridade. Vinda do direito, a prova desempenhará também um importante papel para a filosofia e o pensamento científico.

Mas o ser do documento provatório não é uma abstração. Assim por exemplo, para a linguística a prova é uma fixação e controle do significado textual permitido pelo documento e referendado pela instituição que o gera e na qual ele se agencia.

Além de informar, o documento quer sempre dizer a verdade. $O$ artigo científico é escrito com esse desejo, vem imbuído dessa índole, vem recheado de enunciados que lutam para convencer as pessoas de que os resultados de pesquisas, que conceitos e classificações apresentadas são suficientemente razoáveis para sustentar enunciados apresentados. E aqui é que a Ciência da Informação pode ser pensada como uma ciência neoliberal. Isso porque não haverá ciência que possa prescindir do documento, pois o documento é o fim último de toda ciência, que estabiliza conhecimentos e enunciados quando em seus artigos publica resultados de uma pesquisa, quando neles descreve resultados de uma observação prática, quando aponta resultados numéricos derivados de análises de laboratórios.

"Stability is not a product of representations that fill in the gaps of an incomplete picture of nature, but of the complex and historically variable interactions between various literary, material, and social technologies" (Frohmann, 2004, p. 246). E para reforçar pode-se citar Maira Grigoleto e Eduardo Murguia (2015, p. 8):

O documento passa a ser pensado, pela episteme científica, como um instrumento fundamental para a compreensão dos atos de documentar e escrever, elementos estes que dão estabilidade a diversos fenômenos e garantem validação aos produtos de um dado saber institucional (científico, político, governamental). Tais capacidades, portanto, ultrapassam 
as ações de comunicar, informar e inscrever. A condição do vir a ser do documento é a sua estabilidade no lugar/espaço da materialização.

Pela possibilidade de alicerçar em si as estabilizações que os documentos se tornam tão valiosos em face da ciência e, por conta desse caráter próprio que lhes é intrínseco que a Ciência da Informação possa ser vislumbrada como uma ciência que, diante do mundo neoliberal, goza de certo privilégio, pois está sempre munida de ferramentas que fortalecem seu discurso moderno ou pós-moderno, ainda que o seja.

Por mais fragmentado que o mundo possa o ser, o mundo da ciência neoliberal também não escapa das mazelas do mercado voraz, de uma economia que tudo deglute e do mundo financeiro voraz. No entanto, a necessidade de estabilizar enunciados, um caráter estritamente moderno em sua concepção, não passou e permanece sendo fundamental para toda e qualquer ciência produzir as suas próprias verdades. $\mathrm{E}$ ainda que moderna, é neoliberal por vocação pela sua necessária condição de inscrever a realidade científica, em novos moldes, diversos de modelos anteriores pensados para a ciência nos séculos XVIII e XIX e que quiçá, poderão ser novos para os próximos tempos.

\section{Notas}

(1) Vide artigo de Edgardo Lander (2005), no qual trata do mercado e sua relação com as ciências biotecnológicas e de biomedicina nos Estados Unidos e de como esse mercado cresce e fazer crescer esse campo científico.

\section{Referências}

Bourdieu, Pierre (2015). L'essence du néolibéralismo. // Le monde diplomatique. http://www.monde-diplomatique.fr/1998/03/BOURDIEU/3609 (2015-07-14).

Bush, Vannevar (1945). As we may think. http://www.theatlantic.com/magazine/archive/1945/07/as-we-may-think/303881/ (2015-07-14).

Bush, Vannevar (2008). Science, the endless frontier. Londres/UK, Lightning Source.

Friedman, Milton (1985). Capitalismo e liberdade. São Paulo: Nova Cultural.

Frohmann, Bernd (2004). Deflating Information: from science to documentation. Toronto/Canadá: University Press.

Foucault, Michel (2008). Arqueologia do saber. Rio de Janeiro. Forense Universitária.
Grigoleto, Maira; Murguia, Eduardo Ismael (2015). As bases epistemológicas do patrimônio institucionalizado. // Tendências da Pesquisa Brasileira em Ciência da Informação. 8:2. Disponível em: http://inseer.ibict.br/ancib/index.php/tpbci/article/view/194/243 (2015-12-02).

Gónzalez De Gómez, Maria Nélida (2003). O contrato social da pesquisa: em busca de uma nova equação entre a autonomia epistêmica e autonomia política. DataGramaZero - Revista de Ciência da Informação. 4:1.

Gónzalez De Gómez, Maria Nélida (2015). Validade científica: da epistemologia à política e à ética. Liinc em Revista. Rio de Janeiro. 11:2. 339-359. http://www.ibict.br/liinc (2015-12-02).

Harvey, David (1998). Condição pós-moderna: uma pesquisa sobre as origens da mudança cultural. São Paulo: Ed. Loyola.

Hayek, Friedrich von (1946). O caminho da servidão. Rio de Janeiro: Livraria do Globo.

Hayek, Friedrich von (2011). Principios de un orden social liberal. Madrid/Espanha: Unión Editorial.

Lander, Edgardo (2005). La ciéncia neoliberal. Revista Venezoelana de Economía y Ciencias Sociales. Caracas/Venezuela.11:2. http://www.scielo.org.ve/scielo.php?script= sci arttext\&pid=S1315-64112005000200003\&lng=pt\&nr $\mathrm{m}=$ iso $(2015-12-02)$.

Latour, Bruno; Woolgar, Steve (1997). A vida de laboratório: a produção dos fatos científicos. Rio de Janeiro: Relume Dumará.

Latour, Bruno; Woolgar, Steve (2012). Reagregando o social: uma introdução à teoria do ator-rede. Salvador/Bauru: EDUFBA-EDUSC.

Lévi-Strauss, Claude (1997). O pensamento selvagem. Campinas/SP: Papirus.

Mises, Ludwig von (1977). Uma crítica ao intervencionismo. Rio de Janeiro: Instituto liberal/Nórdica Ed.

Murguia, Eduardo Ismael (2010). Documento e instituição: produção, diversidade e verdade. // Marcondes, Carlos Henrique; Rodrigues, Ana Célia (Org.). Documento: gênese e contextos de uso. Niterói: EdUFF. 123-140.

Oliveira, Marcos Barbosa de (2011). Formas de autonomia da ciência. Scientiae Studia. São Paulo. 9:3, 527-561. http://dx.doi.org/10.1590/S1678-31662011000300005 (2015-12-02)

Otlet, Paul (2007). El tratado de documentación. Murcia/Espanha: Servicio de Publicaciones Universidad de Murcia.

Rabello, Rodrigo (2009). A face oculta do documento: tradição e inovação no limiar da Ciência da Informação. (Tese de Doutorado). Prog. Pós-Graduação em Ciência da Informação/ UNESP. Marília/SP.

Unesco (2006). Sixty years of science at UNESCO 19451965. Paris/França: UNESCO.

Enviado: 2016-02-21

Aceptado: 2016-04-25. 
